\title{
EVALUATION OF THE TOP-LEVEL RESEARCH INITIATIVE
}

\author{
GÖRAN MELIN
}

DOI: $10.22163 /$ fteval.2019.323

\section{INTRODUCTION}

$\mathrm{T}$ his paper presents an evaluation of an unusual research programme, as it is an example of a supra-national research programme, where five countries joined forces and created a common pot of funds, to be distributed to researchers in the five countries without respect to national origin, only research quality. Cooperation between at least three of the countries was however required in each of the funded projects.

The aim of the paper is to present the programme to a wider audience and especially its outcome with respect to impact of research. Of particular interest is an attempt to evaluate and measure societal impact and societal 'readiness' of the projects that were included in the programme. Towards the end, a discussion is held of what impact that can be expected when funding research of the kind at hand in this case.

\section{THE TOP-LEVEL RESEARCH INITIATIVE}

In the autumn of 2008, the prime ministers of the five Nordic countries met and joined forces to create the largest joint Nordic research and innovation initiative to date: The Top-level Research Initiative (TRI). The budget of the programme was DKK400m over five years ( $€ 50-55 \mathrm{~m})$.

The TRI addressed issues of climate, energy and the environment with the overarching idea to strengthen the Nordic competitive advantage in science and innovation in these areas. The initiative involved the very best agencies and institutions in the Nordic region, and some 200 researchers from universities and research institutions and 63 companies participated. Multi-disciplinary coordination was emphasised, including sciences and social sciences as well as business and industry.

Budgetary funding was divided among the Nordic countries in proportion to their GDP. On top of this, the Nordic Council of Ministers, as well as the Nordic organisations NordForsk, Nordic Energy Research and Nordic Innovation, all contributed to the financing of the TRI. The TRI was organised as a true common pot, with none of the financially contributing partners being guaranteed an equal share of the research grants.

The TRI was a result of an ambition in the Nordic Council to establish a Nordic research arena that would increase the level and ambition of collaboration among Nordic research as well as creating a basis for enhanced Nordic participation in EU framework programmes. Whereas it today can be concluded that several of the programmes of the TRI not only had the potential to enhance collaboration and to support innovation in key future technology areas, the TRI was tightly coupled with the climate change agenda. Although the aim of the TRI was threefold climate, energy and the environment - accounts of achievements of the TRI seem to stress the fight against global warming.

The research was organised in 20 projects. Each project belonged to one of six sub-programmes with different profile. There were three types of projects: Nordic Centres of Excellence (NCoE) and Integrated Projects. NCoE were large centres for existing Nordic research communities with participants from at least three Nordic countries. The NCoE aim to increase and facilitate cooperation between excellent researchers, research groups or institutions in the Nordic countries to strengthen the communities and enhance the international profile in prioritised areas in the Nordic countries through joint research and researcher training, joint management and leadership, and shared infrastructure.

Integrated Projects were research projects involving research partners from the Nordic countries and more decidedly involving business partners. These projects focused on involving non-academic partners and thus facilitating ties to business and end-users. The IPs included industry partners and operated under four of the six sub-programmes: Energy Efficiency with Nanotechnology, Integration of large-scale wind power, Sustainable biofuels, and Carbon Capture and Storage (CCS). Last, there were a couple of projects that were labelled 'Studies'.

\section{DESIGN; METHODS}

A set of evaluation questions guided the work of the evaluation. There are twelve evaluation questions, organised under four headings.

- Societal and scientific impact of the TRI

1. How has the TRI contributed to societal and scientific impact?

2. In what ways have the TRI funded projects reached out and influenced stakeholders outside the scientific community?

3. In which areas have the TRI been most successful in reaching out?

- Nordic added value of the TRI

4. In what ways have visibility and attractiveness of Nordic research increased in a European and global context?

5. In what ways has the TRI facilitated appropriate division of work and specialisation between the Nordic countries?

6. To what extent have the TRI projects been integrated and fed back into the national research systems?

7. How has the efficient and flexible use of the Nordic resources been ensured?

- Societal readiness for innovation and research

8. How are TRI funded projects distributed on the Societal Readiness Level scale? 
- Applicability and utilisation of the innovation and research outcome

9. In what ways have the activities supported by the TRI contributed to innovation?

10. How has the TRI contributed to knowledge and innovation that serves the needs of business and society?

11. How has the TRI contributed to increased international cooperation in research?

12. How has the TRI contributed to strengthened Nordic international competitiveness?

The focus for the evaluation, thus, was on the results and impact the TRI had, and on the Nordic added value that the programme brought. The concept of Nordic added value is rather vague, but commonly agreed to exist where initiatives or activities are best and most efficiently carried out in a Nordic context rather than on national or EU level.

Data used in the evaluation were collected from a wide range of sources:

- Document studies

- Interviews with 33 individuals

- Self-assessments of funded projects

- eSurvey to project leaders and participants

- Case studies of seven projects

- Bibliometric analyses

\section{RESULTS WITH RESPECT TO IMPACT}

The TRI was ambitious, and several important results and effects can be observed. This was already a conclusion from the final report of the ongoing evaluation, presented in 2014. Now, four years later, the following can be concluded:

\section{- THE RESEARCH FUNDED BY TRI IS GENERALLY OF HIGH OR} VERY HIGH SCIENTIFIC QUALITY

The TRI projects have produced scientific publications that are more cited in high-end journals than would be expected from a statistical viewpoint. The TRI projects produced more high-end scientific publications, and also a broader base of high-end publications. In recent years there continues to be a steady stream of publications.

\section{- THE NCOE HAVE HAD LARGER SCIENTIFIC IMPACT THAN THE INTEGRATED PROJECTS}

This is, of course, to be expected. The Integrated Projects have had more industry-oriented impact, and at the same time attracted a large portion of additional research funding. Some of the Integrated Projects have been able to produce profitable solutions - some of which have been commercialised.

\section{- THE TRI PROJECTS HAVE ATTRACTED A LARGE AMOUNT OF ADDITIONAL FUNDING}

The research carried out in TRI projects in total have attracted at least $€ 73.5 \mathrm{~m}$ in additional funding, or close to 150 per cent of the total budget of the programme. This shows that the research was of high quality, and also highly relevant. The additional funding stems to a large extent from national funding sources, but there are several examples of related re- search projects in EU consortia enabled through the TRI. Among several researchers, there is an impression that additional funding opportunities from Nordic institutions have been few.

\section{- THE TRI LARGELY FUNDED ALREADY ESTABLISHED RESEARCH AND RESEARCHERS}

This was the purpose from the start, and this also partly explains the much better-than-average scientific quality and citing rates.

\section{- THE TRI HAS CONTRIBUTED TO INCREASED AND SUSTAINAB- LE NORDIC RESEARCH COLLABORATION}

The NCoE have been able to more firmly consolidate their collaborations through additional funding from Nordic and EU sources. Due to the fact that the additional funding for Integrated Projects is secured mainly from national funding sources, there is less international cooperation, although some is enabled through EU funding. However, the sustainability of these collaborations depends on availability of continued and relevant funding opportunities. There are several examples of potential international collaborations between research organisations.

\section{- theRE ARE NO CLEAR DIFFERENCES IN IMPACT BETWEEN THE SUB-PROGRAMMES}

There are high-impact projects in all sub-programmes, as well as projects with less impact. That said, it is difficult to label projects with less impact, as this in several cases may still be too early to fully appraise.

\section{- TRI ENABLED RESEARCH COLLabORATIONS that WOULD OTHERWISE NOT HAVE BEEN POSSIBLE}

Although well-established researchers were funded, as noted above, they had not always collaborated before. Through TRI, existing crossborder research collaborations were strengthened, and in several cases included research partners (and in some cases companies) formerly not part of the network.

\section{- TRI ENABLED TO CARRY OUT PROJECTS THAT WOULD OTHER- WISE NOT HAVE EXISTED}

Some of the project ideas would obviously have found other means of funding, but they would then in most cases have been more national in scope.

\section{- THE TRI CONTRIBUTED TO THE TRAINING OF AT LEAST 81 PHD STUDENTS}

This is an important contribution to national and Nordic strengths in these areas. The presupposed Nordic orientation of these researchers' continued professional careers also helps to create Nordic added value, as does the mobility of these individuals.

\section{- PARTICIPATION IN THE TRI PROJECTS CLEARLY CONTRIBUT- ED TO VALUE CREATION AND NEW CONTACTS AND PARTNER- SHIPS FOR THE COMPANY PARTNERS}

For the companies, TRI contributed to increased R\&D cooperation, mainly within the Nordic countries. There are examples where the Integrated Projects had an impact on the development and application of scientific methods for participating companies as well as external companies. 


\section{- THERE ARE SOME EXAMPLES OF CLEAR SOCIETAL IMPACT}

The results from the $\mathrm{NCOE}$ are clearly useful for public policy actors, although there are yet few clear signs of direct policy impact. The results from Integrated Projects have had some influence on public actors, especially in Iceland regarding the country's potential for wind power and for C02 storage. When discussing potential societal impact, the future and potential importance of the large number of PhDs co-funded by the programme, and who thus have received a Nordic perspective and grown a Nordic network, should be noted.

\section{- THE TRI CLEARLY CONTRIBUTED TO NORDIC ADDED VALUE}

All the points above indicate this direction.

\section{SOCIETAL READINESS FOR INNOVATION AND RESEARCH}

Societal Readiness Levels (SRL) is a way of assessing the level of societal adaptation of, for instance, a particular social project, a technology, a product, a process, an intervention, or an innovation (whether social or technical) to be integrated into society. If the societal readiness for the social or technical solution is expected to be low, suggestions for a realistic transition towards societal adaptation are required. The lower the societal readiness is, the better the plan must be for transition. These are the SRL levels:

- SRL 1 - identifying problem and identifying societal readiness

- SRL 2 - formulation of problem, proposed solution(s) and potential impact, expected societal readiness; identifying relevant stakeholders for the project

- SRL 3 - initial testing of proposed solution(s) together with relevant stakeholders

- SRL 4 - problem validated through pilot testing in relevant environment to substantiate proposed impact and societal readiness

- SRL 5 - proposed solution(s) validated, now by relevant stakeholders in the area

- SRL 6 - solution(s) demonstrated in relevant environment and in cooperation with relevant stakeholders to gain initial feedback on potential impact

- SRL 7 - refinement of project and/or solution and, if needed, retesting in relevant environment with relevant stakeholders
- SRL 8 - proposed solution(s) as well as a plan for societal adaptation complete and qualified

- SRL 9 - actual project solution(s) proven in relevant environment The SRL scale is still not a broadly recognised concept, and it was indeed difficult for interviewees to assess projects according to this scale. We therefore chose to focus this assessment on the smaller number of projects that were selected as case studies, altogether seven projects. Also, the SRL scale has several features in common with the more broadly recognised Technology Readiness Level concept. The former, to some extent, mirrors the latter.

Technology Readiness Levels (TRL) are used to assess the maturity level of a particular technology. Each technology project is evaluated against the parameters for each technology level and is then assigned a TRL rating based on the projects progress. There are nine technology readiness levels. TRL 1 is the lowest and TRL 9 is the highest. The TRL levels are as follows:

- TRL 1 - basic principles observed

- TRL 2 - technology concept formulated

- TRL 3 - experimental proof of concept

- TRL 4 - technology validated in lab

- TRL 5 - technology validated in relevant environment (industrially relevant environment in the case of key enabling technologies)

- TRL 6 - technology demonstrated in relevant environment (industrially relevant environment in the case of key enabling technologies)

- TRL 7 - system prototype demonstration in operational environment

- TRL 8 - system complete and qualified

- TRL 9 - actual system proven in operational environment (competitive manufacturing in the case of key enabling technologies; or in space)

Given the difficulties in assessing the projects on the SRL scale, we chose to map the projects on both levels. A comparison of how the projects perform on the TRL scale provides better possibilities to assess how they are positioned on the SRL scale. For the purpose of this paper, where the evaluated projects and their individual characteristics may be less relevant, the outcome of the mapping is shown as an example of how the SRL and TRL scales can be used side by side in order to investigate societal readiness. Figure 1 depicts the seven projects' positions on the SRL and TRL scales.

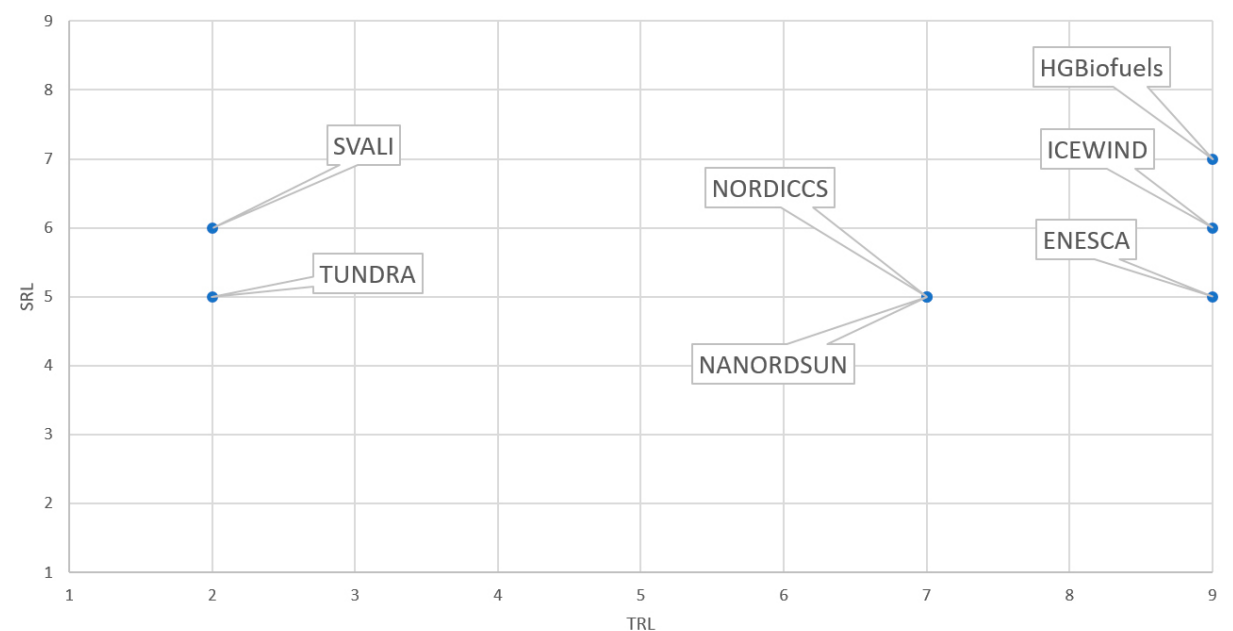

Fig. 1: The projects' positions on the SRL and TRL scales. Source: Technopolis Group 
The mapping of the projects on the two levels shows that six of the seven are at SRL levels 5 and 6 . They are well past the initial stages of identifying and formulating the problem, and address validating proposed solution(s) by relevant stakeholders in the area or demonstrating these solutions in relevant environment and in cooperation with relevant stakeholders to gain initial feedback on potential impact. One project HG Biofuels - is at the stage of refinement of project and/or solution. This suggests that these projects (the solutions) have come a relatively long way to be integrated into society.

The span is larger on the TRL scale. The Integrated Projects (projects with more industrial participation) are, not surprisingly, at higher levels. Some of them have actual systems proven in operational environments and products on the market. Two NCoE (projects of a solid academic character) - SVALI and TUNDRA - are, as is logical, at the other extreme of the TRL scale.

\section{DISCUSSION ABOUT IMPACT OF THE TRI}

No doubt, the TRI was a successful programme. It delivered in accordance with the expectations - and in some cases more. The programme performed well on its overall objectives, in particular those addressing "the highest quality in research and innovation by combining the strongest Nordic communities" and "strengthen national research and innovation systems".

The programme's impact still ought to be put in some perspective. It was indeed the largest Nordic research programme in history, but the total budget was still modest compared to what the Nordic countries invest individually in research in these areas. Just to take one example, the Swedish Energy Agency has an annual budget of around SEK1.6b (close to $€ 160 \mathrm{~m}$ ) for research and innovation in the field of energy for ecological sustainability, competitiveness and security of supply (Government bill 2016). The Agency's mandate and area of support reflect a much larger commitment and a much larger area than that of the TRI, but budget figure does give a perspective to the relative weight of national and Nordic investment in research and innovation, in related research areas. Results and impact that came out of the TRI need to be regarded in this perspective.

While the TRI was a unique effort with strong political backing, it was not enough to radically change the Nordic research landscape in its target research area. That would have required a long-term commitment with subsequent programmes or funding opportunities on Nordic level. It would probably also have required a closer alignment with national priorities and funding schemes. This is an insight that could be taken into account if launching similarly ambitious initiatives in the future.

Neither was the creation of Nordic collaboration as a platform for increased international cooperation within the EU and beyond a central aim for most of the projects and their participants. There is evidence from some projects that this was after all achieved, but it was not necessarily a key driving force or motivation for the researchers when applying for and carrying out research collaboration with funding from the TRI.

The TRI still had a clear Nordic added value. Through the TRI, real cross-border collaboration between researchers and some companies did take place, including networking of importance for PhDs and senior researchers, resulting in several examples of continued collaboration/ contacts. It is likely that the training of the (at least) $81 \mathrm{PhDs}$ will have long-term impact on joint Nordic research, 'marinated' in Nordic collaboration as they are.

\section{REFERENCES}

Arnold E and Eriksson M (2009). Experience from the first Nordic Top Level Research Initiative. See e.g. http://www.toppforskningsinitiativet. org/filer/TRI_brochure_spread.pdf-en

Government bill Sweden (2016). Prop. 2016/17:66 Forskning och innovation på energiområdet för ekologisk hållbarhet, konkurrenskraft och försörjningstrygghet.

\section{AUTHOR}

\section{GÖRAN MELIN}

Technopolis Sweden, Faugert \& Co Utvärdering

Skeppargatan 27, 11452 Stockholm, Sweden 